JIC

22,3

610

Received 28 February 2020 Revised 31 July 2020 30 September 2020

1 October 2020

Accepted 8 November 2020

\section{Strengthening digital collaboration to enhance social innovation capital: an analysis of Italian small innovative enterprises}

\author{
Roberto Chierici and Debora Tortora \\ Department of Business and Law, University of Milan-Bicocca, Milan, Italy \\ Manlio Del Giudice \\ Department of International Business Administration, Link Campus University, \\ Roma, Italy and \\ National Research University Higher School of Economics, Moscow, \\ Russian Federation, and \\ Barbara Quacquarelli \\ Department of Human Sciences for Education, University of Milan-Bicocca, \\ Milan, Italy
}

\begin{abstract}
Purpose - The study aims to investigate whether and how digital transformation, in terms of digital collaboration, joint efforts with internal/external partners to achieve common goals and the adoption of digital tools supporting this practice, affect social innovation capital in the context of small innovative enterprises (SIEs).

Design/methodology/approach - The research hypotheses derived from the analysis of the literature, evaluating how sharing resources, sharing intensity and digital patterns affect the collective capacity of SIEs to innovate, were investigated by applying multiple regression analysis. Data were retrieved from a sample of Italian SIEs through an online survey.

Findings - The main findings suggest that the propensity to spread resources and the sharing intensity positively affect the collective capacity of SIEs to innovate. Also, the effect of resources sharing on collective innovation increases as more digital patterns are used as tools. The connection is weaker for the intensity of resources sharing.

Research limitations/implications - The study is conducted on Italian SIEs, a particular cluster of small and medium enterprises (SMEs). It would be interesting to compare and contrast the results of an analysis of a large sample of international companies, of different sizes and belonging to digital and non-digital sectors.

Originality/value - The results enrich the existing literature on social innovation capital, by clarifying its competitive benefits on the characteristic context of the SIEs and underlining the mediating role of the digital patterns.
\end{abstract}

Keywords Digitalisation, Social capital, Innovation capital, Firms' collaboration

Paper type Research paper

(C) Roberto Chierici and Debora Tortora, Manlio Del Giudice and Barbara Quacquarelli. Published by Emerald Publishing Limited. This article is published under the Creative Commons Attribution (CC BY 4.0) licence. Anyone may reproduce, distribute, translate and create derivative works of this article (for both commercial and non-commercial purposes), subject to full attribution to the original publication and authors. The full terms of this licence may be seen at: http://creativecommons.org/licences/by/4.0/ legalcode

The article is based on the study funded by the Basic Research Program of the National Research University Higher School of Economics (HSE) and by the Russian Academic Excellence Project "5-100".
Journal of Intellectual Capital Vol. 22 No. 3, 2021 pp. $610-632$ Emerald Publishing Limited 1469-1930

DOI 10.1108/JIC-02-2020-0058 


\section{Introduction}

In the age of global hyperconnection, innovation, a fundamental pillar of company competitiveness, although investigated often and with different approaches, needs to be considered in the social process perspective (Hellström, 2004; Doh and Acs, 2010; Franz et al., 2012; de Melo et al., 2020).

Since digital technologies, digital platforms and digital infrastructures extended to macro, meso and micro levels, business innovation processes changed in significant ways, favouring collaboration and knowledge sharing among individuals, firms, other agents and the context (Nambisan et al., 2018, 2019; Malhotra and Majchrzak, 2019; van Wijk et al., 2019).

Even though, from a business viewpoint, collaborational approach has an important role in the development of every organisation, it appears to be crucial especially for those small firms that are engaged in developing innovation. Small firms often lack the abundance of resources (i.e. human capital, financial resources and so on) required to engage in sole complex innovative projects (Hannan and Freeman, 1984; Freel, 2000; Ko et al., 2020). Hence, collaboration represents a way to overcome this physiological lack of resources. Accordingly, as theoretical and practical evidence showed, the concept of innovation has been redefined, going beyond the boundaries of technology (i.e. new products/processes), since changes originate from all the elements comprising a firm's business model. Innovation moved on from the technology push theory (Freeman, 1994; Rothwell, 1994) to the market pull process (Rothwell, 1992; Brem and Voigt, 2009), continuing towards the coupling innovation process theory (Rothwell and Zegueld, 1985), a combination of the previous two theories, then followed by the functional integration innovation process theory (Imai et al., 1985) and the systems integration and networking innovation process theory (Dodgson et al., 2002). In sum, innovation has been progressively based on models of systems integration and open innovation (Chesbrough et al., 2006; Huizingh, 2011). In particular, open innovation has been defined as a new paradigm in innovation management (Chesbrough and Crowther, 2006). Open innovation emerged in the high-tech context, and it now affects several sectors and industries (Bughin et al., 2008). In short, open innovation refers to the formal and informal linkages of external collaboration in which an organisation engages with the actors of the ecosystem to foster its innovative performance (Scuotto et al., 2017a). Also, previous studies investigated the degree of openness to exploring new knowledge sources across organisation boundaries, contributing to expand existing internal knowledge with a higher level of innovation (Wang et al., 2020). Hence, the boundaries between internal and external sources of innovation disappear among the many and various actors in the innovative process.

In other words, the capacity for innovation does not exclusively lie within corporate contexts using a firm's own resources. It is nourished by external relationships, with the emphasis on cooperation (Katz et al., 2013) in the innovative process (Sisodiya et al., 2013; Salter et al., 2014; Rubera et al., 2015). The relational behaviour of the players involved is interlinked with knowledge resources (Hayter, 2013), from mere access to partners' knowledge platforms to the transfer of information and know-how to the co-production of new knowledge, requiring organisations to be increasingly complex (Klerkx and Aarts, 2013). Hence, by adopting a collaborative business model, innovation value is generated by a combination of complementary resources (Eppler et al., 2011; Eppler and Hoffmann, 2012; Rohrbeck et al., 2013). Inflows and outflows of knowledge are used to accelerate internal innovation and extend markets for the external use of innovation. On the one hand, new ideas flow into a firm in an inbound process of open innovation. On the other hand, the outbound process enables external organisations to acquire internally developed innovations and to commercialise them, thanks to more suitable business models (Brunswicker and Wim Vanhaverbeke, 2015).

Nevertheless, in this context, it is important to avoid the creation of exclusively pathdependent innovation knowledge from external sources. Thus, organisations should develop
Italian small innovative enterprises 
$\mathrm{JIC}$

22,3

612

internal capabilities and practical tools and systems to manage and integrate the different sources of knowledge, both internal and external (Ferraris et al., 2017). In this context, an interesting area of investigation examines the contribution of digital transformation-the process of exploiting digital technologies and supporting capabilities to create a robust new digital business model (Gartner, 2019)-to intra- and inter-organisational collaboration to help enterprises with their innovation. The existing literature has underlined specific aspects of digital transformation. Some authors focused on the organisational dimension, stressing the integration of digital technologies and business processes in a digital economy (Liu et al., 2011). Others analysed the changes digital transformation has brought to the business model, in the form of product innovation or organisational structures or the automation of processes (Hess et al., 2016). Some studies took into consideration the use of new digital technologies (social media, mobile devices, analytics or embedded devices) to enhance customer experience, streamline operations or create new business models (Fitzgerald et al., 2014). Apart from the definition, the most relevant trait consists of the underlying strategic vision of the firms rather than the technologies applied (Warner and Wäger, 2019). Indeed, the strategic orientation enables organisations to follow the needs of customers by using new digital technologies to handle valuable information. In this way, digitalisation has opened up a wide range of possibilities for firms to interact with stakeholders, especially regarding the search for novel solutions, new offerings or innovation processes. Digital technologies enable information sharing among the actors of a network or ecosystem of innovation (Del Giudice and Maggioni, 2014), supporting the process of knowledge acquisition, dissemination and exploitation (Scuotto et al., 2017b). In sum, digital tools support enterprises in acquiring and managing the intangible assets of firms, such as intellectual capital (IC), concerning the distinctive knowledge, abilities, values and methods of a firm (Bayraktaroglu et al., 2019), in a social manner, to promote innovative ideas, products and processes. In this vein, social innovation capital (SIC) is a particular kind of IC, which refers to the collective capacity of a firm to innovate, underlying its fundamental aptitude to learn, innovate and adapt (McElroy, 2002), thereby generating competitive advantages. The recognition of the significance of SIC in firm performance and competitiveness requires its active support and management.

In that sense, the aim of the paper consists in understanding whether and how firms can engage in collaborations with their partners to enhance their ability to acquire and exploit knowledge to generate innovation. In particular, the study contributes to better clarify the role collaboration-in terms of collective capacity to innovate-plays in the context of small innovative enterprises (SIEs), extending the current knowledge about how this particular kind of organisation could enhance their capability to innovate by exploiting and reinforcing their SIC. In particular, the study aims to shed some light on the contribution that the resource sharing and the sharing intensity offer to the generation of SIC.

Furthermore, the study takes into account the contribution that digital patterns, in terms of digital tools adopted by firms, could add to the radical shifts digitalisation generates. Digital tools support innovative projects, enabling firms to provide mutual support, enhancing conversation among partners and reinforcing relationships. Hence, the research enriches the existing literature on SIC, by applying digitisation as an effective resource for innovation, instead of a mere context of or tool for innovation. On this vein, the study clearly underlines the mediating role of the digital patterns on the SIC of the SIEs.

The present study aims to add to the present understanding of SIC by investigating digital transformation in terms of digital collaboration. This paper, performed in the particular research setting of Italian SIEs, characterised by being strictly engaged in the innovation processes, despite a feasible limitation of means, and by having higher-level human capital. These peculiarities constitute a trait of interest to investigate on SIC development. Hence, the study contributes to the recent debate regarding SIC by providing a better explanation of whether and how digitalisation, in terms of digital collaboration and digital tools, supports 
SIEs in developing their SIC. In sum, the focus of the study is on the joint efforts with partners to achieve common goals, the digital tools that favour these practices and their effects on SIC.

Therefore, to better underpin and enhance these considerations, the paper is structured as follows. The second section, succeeding the introduction, reflects on the effects of digital transformation on SIC, showing the main realms of IC, social capital (SC) and SIC research. Also, the principal constructs underlying the research objectives are highlighted. The third section describes the research design used for the empirical analysis, the research hypothesis and data collection on a sample of 82 SIEs in Italy. Next, the results of the online survey are presented and discussed, highlighting the emerging business model for innovation applied collaboratively by the SIEs and the effective contribution of the digital tools used. These considerations encourage the evaluation of the emergence of a more updated measurement of SIC, which considers spread and effectiveness of digital tools, contributing to the innovation value creation, value proposition and value capture of SIEs. To conclude the paper, theoretical and managerial implications and limitations are outlined, together with some recommendations. Therefore, considering the collaborative approach, the paper offers a fresh perspective on the role of SIC in supporting more effective innovative performance in Italian SIEs.

\section{Context of analysis}

As shown in several studies, unlike big corporate enterprises, SMEs are more eager to build efficient and durable relationships in their ecosystem to develop intangible resources (human, technological and knowledge) to convert them into value and innovation (Parida et al., 2012). Among them, a cluster of interest for the present analysis is represented by SIEs. According to Italian legislation-Decree-Law 3/2015, known as "Investment Compact" and converted into Law 33/2015-a broad range of companies beyond innovative start-ups are considered to be "innovative SMEs", regardless of the sector, provided they are characterised by an explicit innovation content (Italian Ministry of Economic Development, 2019). These SMEs need to respect some requirements: being incorporated as limited companies, including cooperatives; having their headquarters in Italy or in another Member State of the European Union or of the European Economic Area; having a production facility or branch located in Italy; having their latest financial statements drawn up by an auditor or an audit firm recorded in the register of auditors; not having shares listed on a public regulated market and not being registered in the special section of the Business Register dedicated to innovative start-ups and certified incubators. Also, these firms need to fulfil at least two of the following criteria: (1) Research and development expenditure corresponds to at least $3 \%$ of the higher value between turnover and annual costs (as per the latest approved financial statement); (2) At least onefifth of the total workforce is made up of $\mathrm{PhD}$ holders, $\mathrm{PhD}$ students or researchers or at least one-third hold a master's degree; (3) The company is the owner or licensee of a registered patent (or it has filed an application for an industrial property right) or it owns original registered software (Italian Ministry of Economic Development, 2019). Finally, these firms can obtain the status of innovative SMEs by registering in a special section of the Business Register created ad hoc by the Chambers of Commerce. Hence, despite a feasible limitation of means, these companies distinguish themselves from other organisations in the market by being strictly engaged in innovation processes and by having higher-level human capital.

\section{Theoretical background and study hypotheses}

In the enterprises mentioned above, innovation constitutes a deoxyribonucleic acid (DNA) trait, allowing the enterprises to accumulate knowledge and technological capacities, to improve productivity, to reduce costs and to improve competitiveness. Much of the innovation generated by these firms depends on intangible assets and on the knowledge they possess or may be obtained from external contributions. In other words, internal knowledge

\section{Italian small innovative enterprises}


JIC

22,3

614

(such as the competences of employees), attitudes, aptitudes, intellectual agility, good relations or the ability to generate them, and adequate organisational technology, affect the capacity of the firm to achieve sustainable success (Mariz-Perez et al., 2012). The literature on the topic refers to the interaction of the various classes of intangibles as IC or the knowledge that is valuable in an organisation (Campanella et al., 2014). This knowledge commonly consists of three elements: human capital, organisational or structural capital and SC (Dost et al., 2016).

However, several resource barriers to engaging in innovation are widely recognised, especially for SIEs. Some innovative SMEs suffer more than other companies from lack of physical, organisational and financial resources. They can lack adequate resources to exploit their knowledge stock. Also, they experience a higher level of complexity in attracting the best professionals and in optimising their technology. Unlike their larger competitors, SIEs have difficulty launching big innovation projects due to the level of resources required. This difficulty can arise despite the investment of a considerable portion of their budgets in research and development $(R \& D)$, often at the expense of other business activities and requiring increased risks. The exploitation of external knowledge may constitute a good opportunity for SIEs to overcome these obstacles (Kearney and Mchattie, 2014), allowing access to the intangible assets of partners, thanks to more or less formalised relations. Previous studies on SMEs demonstrated that proficiency in applying open innovation by collaborating with network partners could help these firms to develop new technological combinations, and thus address or take advantage of more market opportunities. Also, by exploiting technology developed elsewhere, SIEs can fill in their internal technological gaps and increase the speed and quality of innovative activities (Parida et al., 2012). In this manner, SIEs may fill the gap between required and available resources for the innovation process.

Digital transformation may facilitate this approach. Hence, the paper attempts to identify the elements of IC that contribute to guaranteeing the collective innovation capacity of SIEs, paying special attention to digital collaboration on SIC.

\section{Intellectual capital}

IC is a multi-dimensional concept linked to knowledge, experience and the practical capabilities of a company. Its effective management can help a company to improve its position in the competitive arena. All the purely intellectual assets that a firm owns that can be used to achieve competitive advantages are recognised as components of the IC (Stewart, 1997; Sullivan, 1998; Hussinki et al., 2017). Many studies conducted on different sectors and countries underlined the contribution of IC to firm performance and value creation (Ulum et al., 2014; Vishnu and Gupta, 2014; Hashim et al., 2017; Sardo and Serrasqueiro, 2017; Bayraktaroglu et al., 2019; Xu and Li, 2019). Value creation consists of the shaping of information, knowledge and innovation. E-commerce, for instance, in the early stages, represented a new type of value transaction based on the shape of value constellations with temporary role participants and high growth potential (Edvinsson, 2000).

Hence, going beyond the definition of Edvinsson and Malone (1997), identifying the two main elements in IC, human capital and structural capital (Petty and Guthrie, 2000), IC is traditionally viewed as having three components (Buenechea-Elberdin, 2017; McDowell et al., 2018). The three components are as follows: (1) human capital, the resources created from the stock and flow of knowledge shared among employees within a firm (Marimuthu et al., 2009); (2) structural or organisational capital, defined as the extraordinary value created by intangible assets, practices, databases, leadership, strategy and organisational design enabling optimal resource orchestration (Miles and Van Clieaf, 2017); (3) SC, the resources derived from the network of relationships possessed by an individual or a social unit (Nahapiet and Ghoshal, 1998). Some studies also include renewal capital (Kianto, 2008), entrepreneurial capital (Erikson, 2002) and trust capital (Mayer et al., 1995). Due to its link with value creation 


\begin{tabular}{|c|c|c|}
\hline Authors & Theory & Contribution to innovation \\
\hline Kaplan and & Integral Credit & Innovation is not considered as a capital alone but it \\
\hline Norton (1992) & Scorecard Model & $\begin{array}{l}\text { constitutes an internal process that increases the value of } \\
\text { human capital, informational capital and organisational } \\
\text { capital }\end{array}$ \\
\hline Edvinsson (1997) & $\begin{array}{l}\text { Skandia Navigator } \\
\text { Model }\end{array}$ & $\begin{array}{l}\text { Innovation is linked to the contribution of human resources to } \\
\text { the organisation }\end{array}$ \\
\hline Bontis (1996) & $\begin{array}{l}\text { University of Western } \\
\text { Ontario Model }\end{array}$ & $\begin{array}{l}\text { Innovation is the result of the communication and learning } \\
\text { processes of individuals that take place in the organisation }\end{array}$ \\
\hline Sveiby (1997) & $\begin{array}{l}\text { Intangible Assets } \\
\text { Monitor }\end{array}$ & $\begin{array}{l}\text { Innovation is considered to be a first-class factor in } \\
\text { accordance with indicators of growth and renovation, } \\
\text { efficiency indicators, stability indicators }\end{array}$ \\
\hline $\begin{array}{l}\text { Camisón et al. } \\
(2000)\end{array}$ & Nova Model & Innovation is considered as an individual capital on its own \\
\hline Euroforum (1998) & Intellect Model & $\begin{array}{l}\text { Innovation regards the future capacity of people and teams to } \\
\text { generate tacit and explicit knowledge }\end{array}$ \\
\hline Bueno et al. (2004) & Intellectus Model & $\begin{array}{l}\text { Innovation is generated through technological capital (within } \\
\text { others factors) and it acts as a link between internal values } \\
\text { that arise from } \mathrm{HC} \text { and organizational capital and external } \\
\text { values related to business and social capital }\end{array}$ \\
\hline
\end{tabular}
innovation"
Italian small innovative enterprises

615

Table 1.

IC models and company innovation

(Chang and Hsieh, 2011), there is a connection between IC and innovation (Subramaniam and Youndt, 2005; Campanella et al., 2014; McDowell et al., 2018), as shown in Table 1.

In sum, an organisation's innovation process depends, to a great extent, on a firm's knowledge base and on the knowledge that a firm can generate in its internal and external networks that constitute the SC of a firm.

\section{Social capital}

The unstoppable assimilation of the social dimension in business and individual activities is a characteristic trait of the knowledge society. Therefore, many scholars examined the impact of relational actions on firm performance, aiming to identify and evaluate the intangible assets capable of increasing the market value of a firm (Bueno et al., 2004). These assets are known collectively as SC. Therefore, $\mathrm{SC}$ is a component of IC, and it is based on the resources accumulated in the organisation from a stable network of intra-organisational relationships (Bourdieu and Wacquant, 1992) also in potential terms (Nahapiet and Ghoshal, 1998). SC also includes the social structures that facilitate activity in the network. The emerging network of collaborative relationships favours the development of new knowledge, thanks to the attitude to sharing knowledge (cognitive dimension) between the actors, perceiving themselves as a part of a network (structural dimension), with a sense of confidence and mutual obligations (relational dimension) (Kim and Shim, 2018). Therefore, SC involves a set of values and subsequent indicators like trust, confidence, loyalty, sincerity, compromise, transparency, solidarity, responsibility, honesty and ethics (Prusak and Cohen, 2001; Bueno et al., 2004; Camps and Marquez, 2014).

When revising the relational capital approach, based on the value of the set of relationships between the firm and its environment, SC considers three categories: intra-SC, in terms of personal relationships within the firm, arranged in communities (virtual or not); inter-SC, referring to the relationships with clients and shareholders and SIC, focused on the dynamic, flexible set of processes and relationships that guide innovation (McElroy, 2002). Moreover, the management of the intrinsic risk and uncertainty involved in collecting and 
JIC

22,3

616

managing information related to innovation activity can be improved. Networks help enterprises to overcome encumbrances (Petrou and Daskalopoulou, 2013; Thompson, 2018), paving the way for cooperation and interaction (Allameh, 2018). SC is also positively related to exploratory and exploitative innovation (Berraies, 2019; Duodu and Rowlinson, 2019). It reduces transaction costs between firms and between firms and other actors, search and information costs and bargaining and decision costs (Landry et al., 2002). These costs are relevant issues for companies but especially for SIEs. The capacity to achieve exploitative (incremental) and explorative (radical) innovation, known as organisational ambidexterity (Vrontis et al., 2017), becomes particularly relevant when the contribution to innovation by external sources is dominant (Wang et al., 2020).

\section{Social innovation capital}

The collective capacity to create valuable, rare and inimitable knowledge (Barney and Hesterly, 2010) and the practice of sharing it among different actors have received increasing emphasis in the analysis of innovation business models (Alguezaui and Filieri, 2010). According to the SC theory, trust, reciprocity, shared values, networking and norms affect this capacity, empowering a feature relevant to IC (Birudavolu and Nag, 2019). In this context, the concept of SIC was introduced in the literature (McElroy, 2002) as a specific component of $\mathrm{SC}$, taking into consideration the collective capacity of a firm to innovate.

Making full use of individual and collective knowledge, and in consideration of the dual nature of the focal actor (individual/organisation) creating/using/sharing knowledge (egocentric vs socio-centric perspective-McElroy et al., 2006), "SIC refers to the structural manner in which social systems (i.e. firms) organise themselves around - and carry out - the production and integration of new knowledge" (McElroy, 2002; Young, 2012). In this perspective, SIC constitutes the source of most of the other forms of SC traceable in a company. Therefore, to comprehend how SIC makes a practical contribution to innovation, it is interesting to analyse patterns of collaboration. The character of a network can reveal archetypical social patterns, with their own tell-tale identity, whose purpose is to produce, spread and apply new knowledge (McElroy, 2002). Communities of practice, for example, as self-organising systems informally bound by what members do together, have an archetypical pattern, characterised by a continually renegotiated joint enterprise. These systems are relationships of mutual engagement uniting members in a social entity and a shared repertoire of communal resources, such as routines, sensibilities, artefacts, vocabulary and styles. Finally, even when answering to an external mandate, it is the community-not the mandate-that produces the practice (Wenger, 1998; Wenger and Snyder, 2000; Duguid, 2005). In the present work, within different kinds of self-organised groups (i.e. networks of practice, open work teams, relationships with suppliers, customers, competitors or business partners with areas of common interest), the policies of management of new knowledge (in terms of production and inclination to share knowledge and spreading of benefits) and of connectedness (technology infrastructures, platforms and digital tools for collaboration) are of particular interest in evaluating the enhancement of SIC in SIEs.

Previous studies suggest that knowledge is critical for a firm to succeed (Grant, 1996). Several theories of firm behaviour have tried to explain the shift from closed to open innovation models and the crucial role played by knowledge sharing and knowledge acquisition in enhancing competitiveness. With specific regard to knowledge sharing, that is the process of interaction, communication and coordination of knowledge (Wang et al., 2014), open innovation encourages access to knowledge among partners since it appears to be as a valuable input. Knowledge sharing potentially supports innovation throughout the whole organisation. In the case of knowledge acquisition, transaction cost of economics theory indicates that firms' activities could aim to achieve minimum production and transaction costs (Williamson, 1989). Therefore, firms could decide not to develop new knowledge 
internally but to collaborate with external partners or to outsource knowledge for cost-saving reasons (Hagedoorn, 1993). Another stream of research advises that firms do not necessarily need to rely on internal knowledge (Barney, 1991; Lavie, 2006). Firms aiming to reinforce their competitive advantage and succeed in a competitive arena, especially in current fast-changing scenarios, could adopt external sources to gain information that could enhance their innovativeness (Brachos et al., 2007) and performance (Wang et al., 2014). Specifically, when obtaining knowledge from several sources, it becomes relevant to analyse the breadth of the search, that is the extent of the search for external knowledge, and the depth of the search, in terms of the intensity of the relationship with each knowledge source (Santoro et al., 2019). This is because firms simultaneously engaged in the depth and breadth of an external knowledge search are more likely to be innovative (Wang et al., 2020). Accordingly, in the current study, considering the search breadth as the propensity to share resources and the search depth as sharing intensity between firms, two research hypotheses can be developed as follows:

H1. The propensity to share resources positively affects the SIC-based performance of SIEs.

H2. The sharing intensity positively affects the SIC-based performance of SIEs.

\section{Digital collaboration and digital tools}

The innovative processes of companies depend, to a large extent, on their capacity to collect and use knowledge from several sources (Del Giudice et al., 2014). Recent studies focussing on SMEs have highlighted the fact that the adoption of different forms of IT may positively affect innovation performance. This is because IT infrastructures seem to play an essential role in supporting knowledge sharing processes (Soto-Acosta et al., 2014a, b, 2017; Mazzucchelli et al., 2019). From this perspective, the tools of digital collaboration, such as applications, social network platforms, blogs, web portals for intra-/inter-firms collaborations, could provide significant reinforcement to shared flows of knowledge, contributing to the generation of new knowledge. Therefore, firms should consider digital transformation as a value network question, giving them access to a wide range of digital systems to manage their interactions with different actors in their networks (Ferreira $e t$ al., 2019). SIEs capable of developing or managing strong digital collaboration tools can establish better relationships with both internal and external partners, enhancing their ability to innovate. Digital tools for the collaboration of individual workers can lead to new competences and prospects; at a firm level, they provide practical, professional and identity support. Enterprise social software-an integral part of companies' enterprise collaboration systems-with social features including subscribing (following) information or people, commenting or tagging contributions, and so on, are often equipped with extensive "awareness features", which help to recognise new and relevant content (Shubert, 2019). Also, platform-based interactions can help to identify potential consumers (recognised as critical resources for innovation), and, if their motivation is increased, the value of their participation is heightened (Eiteneyer et al., 2019). For instance, user-generated content on social media and online communities represents a form of disruptive cooperation that has substantial potential benefits for the future growth of society. Sales, marketing and the provision of community insights are among the multiple uses of social media (Brem and Bilgram, 2015). Social media can be used as a tool for communication or to develop customer relations management. From the innovation standpoint, social media can facilitate information and knowledge sharing in online communities, especially in relation to product information and customer experiences. Above all, this kind of knowledge is useful in inspiring new product development and idea generation (de Zubielqui et al., 2019). In short, digitisation-and digital tools favouring

\section{Italian small innovative enterprises}


JIC

22,3

\section{8}

collaboration accordingly to the present study-does not merely represent the context for innovation. On the contrary, digital technologies can assume the role of an operant resource, serving as an active ingredient in fuelling innovative initiatives (Nambisan et al., 2019).

Therefore, digital tools can be effectively employed to connect resources, knowledge and capabilities among stakeholders, customers and other organisations, and they can have a critical role in facilitating the interdependencies and knowledge flows that occur in the collaborative innovation processes (Muninger et al., 2019). The knowledge sharing generates the requisite knowledge to transform ideas into innovation outcomes. Therefore, the role of digital tools needs to be deeply analysed, as characteristic collaborative patterns emergenarrowing the choice of digital patterns of collaboration in the present study-in accordance with the SIC viewpoint.

From such a perspective, a further two research hypotheses can be developed as follows:

H3. The higher the digital patterns, the higher is the effect of shared resources on the SIC of the SIEs.

H4. The higher the digital patterns, the higher is the effect of sharing intensity on the SIC of the SIEs.

A conceptual model has been constructed, taking into account the hypotheses mentioned above. The model is presented in the diagram below (Figure 1) and illustrates the relationships investigated.

\section{Methodology}

Research sample and data collection

The study aims to investigate the effects of digital transformation within the SIEs' frameworks. In particular, the paper tries to understand better whether and how firms' propensity to share resources with partners to achieve common goals, the sharing intensity and the digital collaboration, affect SIC. The study uses a quantitative approach to achieve this aim. In particular, a multiple regression analysis is performed to test the hypotheses on data retrieved from a sample of Italian SIEs. The authors consulted a special section of the Business Register of the Italian Chamber of Commerce to identify SIEs for inclusion in the sample. In particular, the pminnovative.registroimprese.it platform, launched in November 2015 and publicly available, allows firms that fulfil specific requirements to register as innovative enterprises at their local Chamber of Commerce to benefit from a vast array of

Figure 1.

Conceptual model

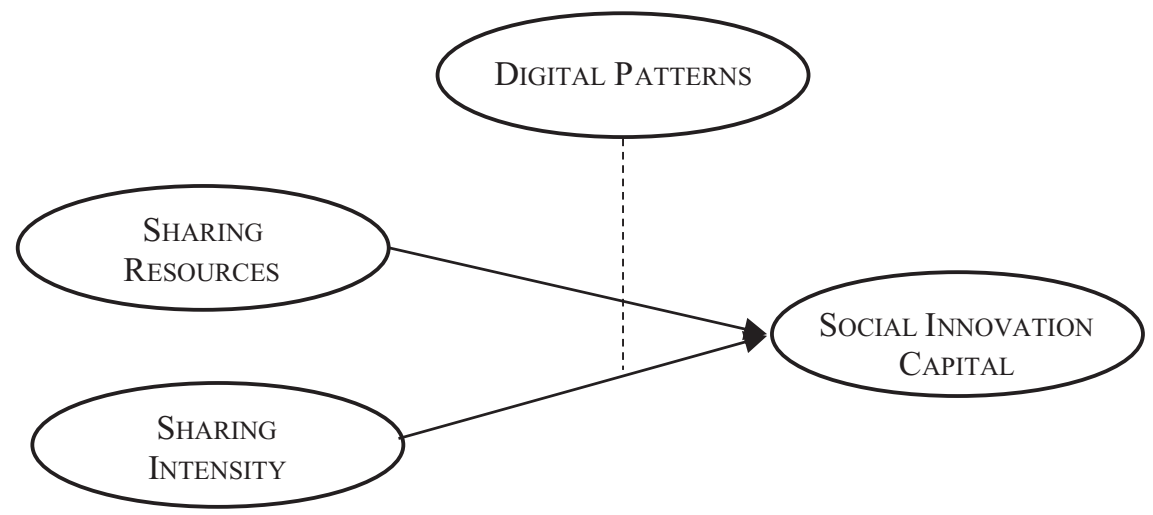


policy measures. This particular section of the Italian Chamber of Commerce website provides a complete business profile of innovative SMEs, updated or confirmed at least once a year (as confirmation of compliance with legal requirements). At the end of November 2019, 1,301 innovative SMEs (excluding innovative start-ups) were registered on the platform, 1,033 of which were classified as SIEs, since they had fewer than 50 employees and a total turnover not exceeding $€ 10 \mathrm{~m}$ (www.pminnovative.registroimprese.it). This subset of Italian SIEs represents the initial database for the present study. After a preliminary screening of the websites of SIEs, it emerged that 327 firms did not declare a contact email address, so the effective database was made up of 706 SIEs. From December 2019 to January 2020, these SIEs were invited to reply to the questionnaire, and 91 questionnaires were returned in a completed form (12.88\% response rate). The research aim is to investigate whether and how SIEs collaborate with partners and exploit the potential of digital transformation to achieve common goals and reinforce their SIC. Nine questionnaires were eliminated because they were incomplete or were from firms declaring non-adoption of digital collaboration. The remaining 82 SIEs make up the final sample of the present study. The questionnaire, in which respondents self-reported their answers, was developed according to previous literature on firms' collaboration, social media digital collaboration, and SIC by focussing on and adapting the scales and key indicators in questionnaires used in previous studies. In particular, the online questionnaire was structured in two sections: the first part was used to collect data about the investigated variables to examine the existing relationship among them and to obtain information on the research topic; the second section collected information about the investigated SIEs, such as field of activity, sales revenue and business form. Additionally, to reduce the risk of common method bias, throughout the data collection process, respondents were not informed about the aim of the study, and the dependent and independent variables were presented to interviewees in different positions in the questionnaires (Jahanmir and Lages, 2016).

As shown in Table 2, the majority of the interviewed firms are limited liability companies $(8.4 \%)$, followed by limited companies $(11 \%)$, individual companies $(2.4 \%)$ and unlimited partnerships $(1.2 \%)$. Regarding the target market, more than half of the firms operate at international level $(54.9 \%)$, followed by those operating at national $(36.6 \%)$ and regional levels $(8.5 \%)$. Regarding sectors, firms providing services are the most numerous $(57.3 \%)$, followed by manufacturing firms $(32.9 \%)$ and, finally, the commercial services sector with the lowest percentage $(9.8 \%)$.

\begin{tabular}{|c|c|c|}
\hline & Frequency & Percentage $(\%)$ \\
\hline \multicolumn{3}{|l|}{ Company type } \\
\hline Individual company & 2 & 2.4 \\
\hline Limited liability company & 70 & 85.4 \\
\hline Unlimited partnership & 1 & 1.2 \\
\hline Limited company & 9 & 11.0 \\
\hline \multicolumn{3}{|l|}{ Target market } \\
\hline Regional & 7 & 8.5 \\
\hline National & 30 & 36.6 \\
\hline International & 45 & 54.9 \\
\hline \multicolumn{3}{|l|}{ Industry } \\
\hline Manufacturing & 27 & 32.9 \\
\hline Commercial services & 8 & 9.8 \\
\hline Services & 47 & 57.3 \\
\hline
\end{tabular}

Italian small innovative enterprises$$
\text { lowest percentage }(9.8 \%) \text {. }
$$ 
All measures of the independent variables, namely sharing resources, sharing intensity, and digital patterns, were adopted from previous studies to suit the research context better. They were evaluated on a seven-point Likert scale, ranging from 1 (strongly disagree) to 7 (strongly agree).

Regarding sharing resources, respondents had to evaluate their firms' intention to cooperate with other innovation partners in terms of sharing proprietary information, innovative ideas, market opportunities and intermediate goals preparatory to achieving the main results. This four-item scale was adapted from Richey and Autry (2009). The second independent variable, namely sharing intensity, was evaluated using a three-item scale adapted from Faems et al. (2005). Respondents had to evaluate their firms' readiness to set up innovation-related projects with partners, customers and universities and research centres, respectively. Finally, a third independent variable that works as moderator, namely digital patterns, was measured using four items adapted from Trainor et al. (2014) and provides a measure of firms usage of social media to develop innovative projects, sharing mutual support, establishing conversations and reinforcing relationships with partners.

The dependent variable, SIC, was evaluated using a four-item scale adapted from Kijek (2012). SIC concerns the capacity of a firm to organise itself around the generation and exploitation of new knowledge. Therefore, respondents had to evaluate firms' SIC by expressing an opinion about their firms' cooperation between research and development, production and marketing departments, their capacity to generate patents or patent claims, their propensity to exchange knowledge in the social environment and their incentives for innovative partners.

Additionally, based on the literature review, several control variables were included in the questionnaire to avoid bias. The size of a firm could significantly affect its ability to organise processes, allowing the creation and exploitation of knowledge; therefore, firm size was included in the analysis. This particular control variable was evaluated using annual turnover. Finally, the study takes into account the industry as a control variable because the field of activity seems to shape the usage of social media in developing innovative projects. The sector of activity variable was measured as a dummy variable for each industry: manufacturing, commercial services and services.

\section{Measurement scale validation}

Cronbach's alpha was calculated to assess the reliability coefficient of the variables adopted in this study (Hair et al., 2006). The results show that all construct measures proved to be reliable or close to reliable, according to the commonly employed Cronbach's alpha cut-off value of 0.70 (Nunnally and Bernstein, 1994). Concerning the convergent validity test, the study checked item loadings, and they all turned out to be equal or greater than the recommended threshold of 0.50 (Hair et al., 2006); all the composite reliability (CR) values exceed the minimum threshold of 0.70 (Bagozzi and Yi, 1988; Nunnally and Bernstein, 1994). Finally, the average variance extracted (AVE) was checked, and the results confirm that all values are over the conventional threshold of 0.50 (Fornell and Larcker, 1981). Table 3 presents the reliability and CFA results.

\section{Analysis and results}

The study aims to examine three different models. In particular, the hypotheses were investigated by running a multiple regression analysis using Statistical Product and Service Solutions (SPSS) 25. The decision to adopt a quantitative technique to study the investigated topic and assess the survey data using an ordinary least squares (OLS) regression analysis 
appears to be appropriate and justified because previous studies have called for a more finegrained understanding of the contribution SIC could offer to firm innovativeness (McElroy, 2002). The choice to adopt a quantitative method was in line with the proposed research and with previous studies (Duodu and Rowlinson, 2019). It was based on the analysis of the relationship between sharing resources and sharing intensity (independent variables) and their effect on SIC (dependent variable). The OLS regression results are presented in Table 4.

With specific regard to model 1 , exploring the direct effect of sharing resources and sharing intensity on SIC, results show a moderate goodness of fit $\left(R^{2}=0.415\right)$. Model 1 shows a significant relationship between the firms' sharing of resources and SIC, as well as the intensity of the collaboration between SIEs and their partners and the level of SIC. Hypothesis 1 and Hypothesis 2 are both confirmed because the effect of sharing of resources on SIC is significant and positive $(B=0.264 ; T=3.071 ; p<0.01)$, and the effect of sharing intensity on SIC is significant and positive $(B=0.312 ; T=4.213 ; p<0.01)$. Model 2 was proposed to test the moderating effect of digital patterns on the relationship between resource sharing and SIC. The model shows an acceptable goodness of fit $\left(R^{2}=0.449\right)$, and the moderating effect turned out to be positive and significant $(B=0.056 ; T=2.140 ; p<0.05)$, confirming H3. Finally, model 3 presents a moderate goodness of fit $\left(R^{2}=0.437\right)$ and tests the moderating effect of digital patterns on the relationship between sharing intensity and SIC, which emerged as not significant $(B=0.044 ; T=1.688)$, rejecting H4.

The models also indicate that firm size and industry have a significant effect as control variables. Specifically, firm size affects SIC positively, as shown in models 1, 2 and 3, while being in the manufacturing business affects SIC negatively. Finally, being in the commercial services industry seems not to have a significant effect on SIC.

Furthermore, since multicollinearity among independent variables could occur when performing multiple regression analysis, the authors checked for variance inflation factor (VIF). Since VIF statistics do not show values higher than five (Hair et al., 2010), multicollinearity is not a relevant problem, and it could be assumed that the models fit the data retrieved from the online questionnaire.

\begin{tabular}{|c|c|c|c|c|}
\hline & $\alpha$ & CR & AVE & \\
\hline Sharing resources & 0.66 & 0.71 & 0.50 & \\
\hline Sharing intensity & 0.70 & 0.72 & 0.51 & Table 3. \\
\hline Digital patterns & 0.73 & 0.75 & 0.55 & Reliability and CFA \\
\hline Social innovation capital & 0.73 & 0.75 & 0.53 & results \\
\hline
\end{tabular}

Italian small innovative enterprises

\begin{tabular}{lccc}
\hline & Model 1 & Model 2 & Model 3 \\
\hline Constant & $3.501(8.403)^{* *}$ & $3.685(8.856)^{* *}$ & $3.627(8.670)^{* *}$ \\
Sharing resources (SR) & $0.264(3.071)^{* *}$ & $-0.026(-0.162)$ & $0.227(2.580)^{*}$ \\
Sharing intensity (SI) & $0.312(4.213)^{* *}$ & $0.344(4.657)^{* *}$ & $0.152(1.271)$ \\
Digital patterns (DP) & & $1.220(3.140)^{* *}$ & $1.187(3.020)^{* *}$ \\
SR * DP & & $0.056(2.140)^{* *}$ & \\
SI * DP & & & $0.044(1.688)$ \\
Annual turnover (Firm size) & $-0.608(-2.551)^{*}$ & $-0.784(-3.174)^{* *}$ & $-0.732(-2.967)^{* *}$ \\
Industry-manufacturing & $-0.321(-1.354)$ & $-0.399(-1.705)$ & $-0.375(-1.589)$ \\
Industry-commercial services & $0.386(1.096)$ & $0.268(0.768)$ & $0.290(0.824)$ \\
$R^{2}$ & 0.415 & 0.449 & 0.437
\end{tabular}

Note(s): $N=82 ; * p<0.05 ; * * p<0.01 ; T$-values in parentheses
Table 4 Regression results 


\section{Discussion of the results}

The contemporary information-rich competitive arena and the rapid growth of digital technologies require firms to continuously adapt to the evolving conditions of the environment, developing solutions that allow to generate and manage organisational knowledge. In this perspective, the resources firms generate and acquire from the networks wherein they operate and the structures that enable and accelerate activities among network members appears to be crucial for the knowledge generation and the competitiveness of the firms themselves (Kim and Shim, 2018). Since firms capacity to generate innovation relies on their networks more than ever (Del Giudice et al., 2014), firms are increasingly paying attention on how to develop and nurture their relationships with internal and external partners and, in turn, enhancing their performance and growth (Scuotto et al, 2017a).

In this sense, firms' digitalisation can be considered as an entrepreneurial process (Nambisan et al., 2018), capable of favouring the spread of knowledge within the firm itself and generating more updated business models that may not only erode incumbent advantages but also pinpoint new ways of producing innovation.

The study analysis highlights that the investigated SIEs, operating for the most part at international and national level, have a relevant use of intra-/inter-firm collaboration mediated by digital tools, principally social media, to share resources, both financial and intellectual, and stimulate widespread access to information via new technologies. Due to the technological progress brought about by digitalisation, firms seeking to survive have been adopting digital sources and patterns to find innovative solutions (Liu et al., 2011). In particular, today's competitive landscape requires firms to obtain information and learning from several sources and share knowledge to innovate and successful compete (Santoro et al., 2019; Wang et al., 2020).

On this view, these study results contribute to the recent debate regarding SIC, providing better explanation of whether and how digitalisation, in terms of digital collaboration and digital tools, could potentially support SIEs in developing their SIC. More in detail, SIEs propensity to share resources and their sharing intensity directly affect their SIC-based performance. Additionally, by adopting digital patterns as moderating variable, the study shows that the usage of social media to develop common projects with partners and provide mutual support allows to reinforce the effect that resource sharing has on improving SICbased performance.

From this perspective, the findings of this study confirm that, concerning SIEs, the propensity to spread resources and the sharing intensity positively affect the capacity to innovate. This result is particularly interesting because it confirms the important support digitalisation offers for the formal and informal linkages firms develop with other actors in the same ecosystem. This result also provides additional evidence of the centrality of the open innovation principle in the context of SIEs. The results also suggest that the effect of shared resources on collective innovation increases progressively as digital patterns grow, in terms of the tools utilised, while the connection is weaker for the resources sharing intensity.

\section{Theoretical and managerial implications}

The results of this research proffer potentially interesting implications from both a theoretical and managerial viewpoint, as they provide a better understanding of SIC, which represents one of the most important SC forms within a firm, and contribute to shed some light on the role digital patterns play in its generation. From a theoretical viewpoint, the study highlights the fact that digital patterns can be considered a key resource for the value configuration of the innovation activities of SIEs in the profitable selection of knowledge resources and favour-sharing information in promoting innovation and creating a competitive advantage. Furthermore, digital patterns can strengthen digital collaboration, contributing to the 
generation of joint innovation. In turn, this could impact the value creation process by favouring SIEs in the definition of improved value proposition, better starting offering, processes and organisational solutions. Additionally, digital patterns could increase the value generated for SIEs, resulting in more satisfactory use of financial, organisational and knowledge resources. Revenues could be increased as a result of a more appealing offer, more contained costs, better use of human resources and improved value capture.

Finally, digital patterns could favour the spread of value generated by conjoint activities among partners and in society-value spreading-in general, the activation of a virtuous circle. More competitive market positions, resulting from the innovation value process described above, encourage SIEs to pursue the improvement of the digital patterns adopted. The innovation value process, based on digital patterns, can help the supply side and the demand side in a virtuous mechanism of information/knowledge, transforming and renewing the innovative knowledge flowing among users thereby increasing market share, revenues, profitability and value for all the stakeholders involved, as shown in Figure 2.

The findings of this study enrich the existing literature on SIC by clarifying its competitive benefits for SIEs. Moreover, the study contributes to business management literature focused on investigating the processes, and, in particular, those who support firms in developing and managing knowledge (Del Giudice and Straub, 2011). This research helps to explain the issue of the business value of collaborative innovation, by underlining the mediating role of digital patterns, and by investigating the interplay of digital platforms and social media on attitudes to sharing resources. This result is particularly interesting because it adds to the literature investigating social media and the mechanisms through which social media tools contribute to the innovation generation process (Soto-Acosta et al., 2014b; Papa et al., 2018). This study contributes to management literature by offering new insights on the role digital patterns could have in supporting SIEs, a particular cluster of SMEs, in developing their SIC. Where the intensity of sharing is concerned, a decrease in shared resources as the firm became bigger was noted. This could be due to the fact that when SIEs attain better market positions, extend their business and increase in size, they can access other sources of knowledge. Also, on this stage these firms can find easier and quicker solutions to overcoming resource barriers in innovation.

The findings have practical implications, which are positive from a managerial viewpoint. Promoting digital collaboration by investing in social media and other sharing tools may help SIEs to locate physical, knowledge-related and financial resources. In this sense, social media are seen as enablers and drivers of innovation. Managers and entrepreneurs should

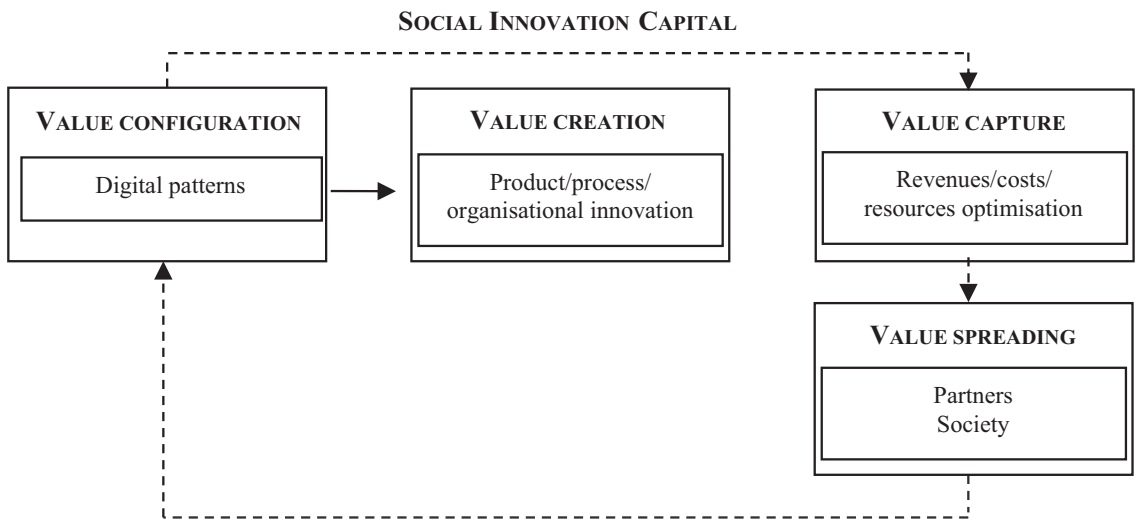

Italian small innovative enterprises 
$\mathrm{JIC}$

22,3

624

encourage their employees to use social media tools, exploiting their capacity for real-time interaction to join intra-firm groups or communities of practice. The aim is to stimulate workers to intercept and exploit external knowledge, but also to deal with peers, to search for solutions to operative issues or to modify organisational routines or practices, which may have an impact on the way employees learn and operate in the innovation processes. Hence, turning to social media for digital tools promoting collaboration seems to be a change in SIEs' business model, which results in observable changes in their practices towards customers, employees and business partners.

\section{Future perspectives of research and conclusions}

SIEs can survive over time and transform themselves into incumbent firms if they can adapt to the environment and face the challenges of the current competitive scenario. Today, digital transformation appears to be not only a choice but a requirement to fully exploit the opportunities offered by the advent of the digital transformation. Among other factors, social media are increasingly becoming networking tools enabling companies to access knowledge from external actors to facilitate the innovation process and the firm performance (de Zubielqui et al., 2019). However, current research literature still offers little guidance on the strategic use of these tools (Muniger et al., 2019), and, as yet, does not promote their use as real digital patterns able to increase firms' innovative performance, especially in the case of small firms. Therefore, the present study aims to contribute to filling this gap by suggesting some implications to be addressed by SIC. Also, the findings may encourage companies to benefit from using social media throughout their innovation processes.

However, even if the findings of this study elucidate the digital openings, it should be mentioned that these openings have their limitations, thereby suggesting avenues for future research. First, the sample size is limited, and the investigated firms are based in Italy. Only half of the sample operates in international markets. To validate the results, future research should try to enlarge the sample, paying attention to small, medium and big innovative companies and including firms operating in other countries. Then, future research could contribute to identify differences and commonalities with foreign markets and provide some interesting comparisons between firms of different sizes. Also, due to the young composition of the present sample, the effect of the age of firms was not taken into consideration. This effect could be analysed to evaluate the relationship between external knowledge search and innovation performance, as previous studies suggested (Li et al., 2019). Furthermore, this study only examines three macro-categories of sectors. It would be useful to perform an in-depth analysis to identify whether and how digital transformation contributes to generating and enhancing the SIC of firms. In addition, it would be useful to conduct other studies to compare and contrast the findings of firms engaged in sectors with significant use of digital tools with others that are less involved in new digital technologies. Finally, future perspectives of research may extend the conceptual model by taking into consideration the conditions under which knowledge flows via digital patterns among partners and measuring the effect of SIC on the innovation generated. Measuring could be financial and non-financial and could use structural equation modelling.

In conclusion, digital patterns can be considered as enablers to seize new opportunities and to update the existing business model by reconfiguring the process of value configuration, value creation, value capture and value spreading, thereby enabling access to knowledge assets, competences and complementary assets and technologies to achieve sustainable competitive advantages. 


\section{References}

Alguezaui, S. and Filieri, R. (2010), "Investigating the role of social capital in innovation: sparse versus dense network", Journal of Knowledge Management, Vol. 14 No. 6, pp. 891-909.

Allameh, S.M. (2018), "Antecedents and consequences of intellectual capital. The role of social capital, knowledge sharing and innovation", Journal of Intellectual Capital, Vol. 19 No. 5, pp. 858-874.

Bagozzi, R.P. and Yi, Y. (1988), "On the evaluation of structural equation models", Journal of the Academy of Marketing Science, Vol. 16 No. 1, pp. 74-94.

Barney, J.B. (1991), "Firm resources and sustained competitive advantage", Journal of Management, Vol. 17 No. 1, pp. 99-120.

Barney, J.B. and Hesterly, W.S. (2010), VRIO frame Work Strategic Management and Competitive Advantage, Pearson, New Jersey.

Bayraktaroglu, A.E., Calisir, F. and Baskak, M. (2019), "Intellectual capital and firm performance: an extended VAIC model", Journal of Intellectual Capital, Vol. 20 No. 3, pp. 406-425.

Berraies, S. (2019), "The effect of enterprise social networks use on exploitative and exploratory innovations. Mediating effect of sub-dimensions of intellectual capital", Journal of Intellectual Capital, Vol. 20 No. 3, pp. 426-452.

Birudavolu, S. and Nag, B. (2019), "Social capital: the innovation culture", Business Innovation and ICT Strategies, Palgrave Macmillan, Singapore.

Bontis, N. (1996), "There is a price on your head: managing intellectual capital strategically", Business Quarterly, Vol. 60 No. 4, pp. 40-47.

Bourdieu, P. and Wacquant, L. (1992), An Invitation to Reflexive Sociology, University of Chicago Press, Chicago, IL.

Brachos, D., Kostopoulos, K., Soderquist, K.E. and Prastacos, G. (2007), "Knowledge effectiveness, social context and innovation", Journal of Knowledge Management, Vol. 11 No. 5, pp. 31-44.

Brem, A. and Bilgram, V. (2015), "The search for innovative partners in cocreation: identifying lead users in social media through netnography and crowdsourcing", Journal of Engineering and Technology Management, Vol. 37, pp. 40-51.

Brem, A. and Voigt, K. I. (2009), "Integration of market pull and technology push in the corporate front end and innovation management-insights from the German software industry", Technovation, Vol. 29 No. 5, pp. 351-367.

Brunswicker, S. and Vanhaverbeke, W. (2015), "Open innovation in small and medium-sized enterprises (SMEs): external knowledge sourcing strategies and internal organizational facilitators", Journal of Small Business Management, Vol. 53 No. 4, pp. 1241-1263.

Buenechea-Elberdin, M. (2017), "Structured literature review about intellectual capital and innovation", Journal of Intellectual Capital, Vol. 18 No. 2, pp. 262-285.

Bueno, E., Salmador, M.P. and Rodríguez, Ó. (2004), "The role of social capital in today's economy", Journal of Intellectual Capital, Vol. 5 No. 4, pp. 556-574.

Bughin, J., Chui, M. and Johnson, B. (2008), "The next step in open innovation”, The McKinsey Quarterly, Vol. 4 No. 6, pp. 1-8.

Camisón, C., Palacios, D. and Devece, C. (2000), "Un nuevo modelo para la medición del Capital Intelectual en la empresa: El modelo Nova", $X$ Congreso Nacional ACEDE, Oviedo.

Campanella, F., Della Peruta, M.R. and Del Giudice, M. (2014), "Creating conditions for innovative performance of science parks in Europe. How manage the intellectual capital for converting knowledge into organizational action", Journal of Intellectual Capital, Vol. 15 No. 4, pp. 576-596.

Camps, S. and Marques, P. (2014), "Exploring how social capital facilitates innovation: the role of innovation enablers", Technological Forecasting and Social Change, Vol. 88, pp. 325-348.

Chang, W.S. and Hsieh, J.J. (2011), "Intellectual capital and value creation-is innovation capital a missing link?", International Journal of Business and Management, Vol. 6 No. 2, pp. 3-12.

Italian small innovative enterprises

$+$ 
Chesbrough, H. and Crowther, A.K. (2006), "Beyond high tech: early adopters of open innovation in other industries", R\&D Management, Vol. 36 No. 3, pp. 229-236.

Chesbrough, H., Vanhaverbeke, W. and West, J. (Eds) (2006), Open Innovation: Researching a New Paradigm, Oxford University Press.

de Melo, M.F.D.S., Yaryd, R.T., Souza, R.C. and Campos-Silva, W.L. (2020), "How social impact and innovation have been related in the academic literature?", Future Studies Research Journal: Trends and Strategies, Vol. 12 No. 1, pp. 125-147.

de Zubielqui, G.C., Fryges, H. and Jones, J. (2019), "Social media, open innovation \& HRM: implications for performance", Technological Forecasting and Social Change, Vol. 144, pp. 334-347.

Del Giudice, M. and Maggioni, V. (2014), "Managerial practices and operative directions of knowledge management within inter-firm networks: a global view", Journal of Knowledge Management, Vol. 18 No. 5, pp. 841-884.

Del Giudice, M. and Straub, D. (2011), "Editor's comments: IT and entrepreneurism: an on-again, offagain love affair or a marriage?", MIS Quarterly, Vol. 35 No. 4, pp. iii-viii.

Del Giudice, M., Della Peruta, M.R. and Scuotto, V. (2014), "Student entrepreneurship, creativity and success. How much does knowledge heterogeneity really matter?", International Journal of Entrepreneurship and Innovation Management, Vol. 18 No. 1, pp. 45-58.

Dodgson, M., Gann, D.M. and Salter, A. (2002), "The intensification of innovation", International Journal of Innovation Management, Vol. 6 No. 1, pp. 53-84.

Doh, S. and Acs, Z.J. (2010), "Innovation and social capital: a cross-country investigation”, Industry and Innovation, Vol. 17 No. 3, pp. 241-262.

Dost, M., Badir, Y.F., Ali, Z. and Tariq, A. (2016), "The impact of intellectual capital on innovation generation and adoption", Journal of Intellectual Capital, Vol. 17 No. 4, pp. 675-695.

Duguid, P. (2005), “«The art of knowing»: social and tacit dimensions of knowledge and the limits of the community of practice", The Information Society, Vol. 21 No. 2, pp. 109-118.

Duodu, B. and Rowlinson, S. (2019), "The effect of social capital on exploratory and exploitative innovation", European Journal of Innovation Management, available at: www.emeraldinsight. com/1460-1060.htm.

Edvinsson, L. (1997), “Developing intellectual capital at Skandia”, Long Range Planning, Vol. 30 No. 3, pp. 366-373.

Edvinsson, L. (2000), "Some perspectives on intangibles and intellectual capital 2000", Journal of Intellectual Capital, Vol. 1 No. 1, pp. 12-16.

Edvinsson, L. and Malone, M. (1997), Intellectual Capital, HarperBusiness, New York, NY.

Eiteneyer, N., Bendig, D. and Brettel, M. (2019), "Social capital and the digital crowd: involving backers to promote new product innovativeness", Research Policy, Vol. 48 No. 8, pp. 1-15, 103744.

Eppler, M.J. and Hoffmann, F. (2012), "Does method matter? An experiment on collaborative business model idea generation in teams", Innovation, Vol. 14 No. 3, pp. 388-403.

Eppler, M.J., Hoffmann, F. and Bresciani, S. (2011), "New business models through collaborative idea generation", International Journal of Innovation Management, Vol. 15 No. 6, pp. 1323-1341.

Erikson, T. (2002), "Entrepreneurial capital: the emerging venture's most important asset and competitive advantage", Journal of Business Venturing, Vol. 17 No. 3, pp. 275-290.

Euroforum (1998), "Proyecto Intelect. Medición del capital intelectual", Instituto Universitario Euroforum, Escorial, Madrid.

Faems, D., Van Looy, B. and Debackere, K. (2005), "Interorganizational collaboration and innovation: toward a portfolio approach", Journal of Product Innovation Management, Vol. 22 No. 3, pp. 238-250. 
Ferraris, A., Santoro, G. and Dezi, L. (2017), "How MNC's subsidiaries may improve their innovative performance? The role of external sources and knowledge management capabilities", Journal of Knowledge Management, Vol. 21 No. 3, pp. 540-552, doi: 10.1108/JKM-09-2016-0411.

Ferreira, J.J., Fernandes, C.I. and Ferreira, F.A. (2019), "To be or not to be digital, that is the question: firm innovation and performance", Journal of Business Research, Vol. 101, pp. 583-590.

Fitzgerald, M., Kruschwitz, N., Bonnet, D. and Welch, M. (2014), "Embracing digital technology: a new strategic imperative", MIT Sloan Management Review, Vol. 55 No. 2, pp. 1-16.

Fornell, C. and Larcker, D.F. (1981), "Structural equation models with unobservable variables and measurement error: algebra and statistics", Journal of Marketing Research, Vol. 18 No. 3, pp. 382-388.

Franz, H.W., Hochgerner, J. and Howaldt, J. (Eds) (2012), Challenge Social Innovation: Potentials for Business, Social Entrepreneurship, Welfare and Civil Society, Springer Science \& Business Media.

Freel, M.S. (2000), "Barriers to product innovation in small manufacturing firms", International Small Business Journal, Vol. 18 No. 2, pp. 60-80.

Freeman, C. (1994), "The economics of technical change", Cambridge Journal of Economics, Vol. 18, pp. 463-514.

Gartner (2019), Information Technology Gartner Glossary, available at: https://www.gartner.com/en/ glossary.

Grant, R.M. (1996), “Toward a knowledge-based theory of the firm”, Strategic Management Journal, Vol. 17 No. 2, pp. 109-122.

Hagedoorn, J. (1993), "Understanding the rationale of strategic technology partnering: interorganizational modes of cooperation and sectoral differences", Strategic Management Journal, Vol. 14 No. 5, pp. 371-385.

Hair, J.F., Anderson, R.L., Tatham, A. and Black, W. (2006), Multivariate Data Analysis, Pearson Prentice Hall, Upper Saddle River, NJ.

Hair, J.F., Black, W.C., Babin, B.J. and Anderson, R.E. (2010), Multivariate Data Analysis, Prentice Hall, Englewood Cliffs, NJ.

Hannan, M.T. and Freeman, J. (1984), "Structural inertia and organizational change", American Sociological Review, Vol. 49 No. 2, pp. 149-164.

Hashim, M.J., Osman, I. and Alhabshi, S.M. (2017), "Intellectual capital contribution to organizational performance in Malaysian banking and non-banking sectors", Advanced Science Letters, Vol. 23 No. 1, pp. 406-409.

Hayter, C.S. (2013), "Conceptualizing knowledge-based entrepreneurship networks: perspectives from the literature", Small Business Economics, Vol. 41 No. 4, pp. 899-911.

Hellström, T. (2004), "Innovation as social action”, Organization, Vol. 11 No. 5, pp. 631-649.

Hess, T., Matt, C., Benlian, A. and Wiesböck, F. (2016), "Options for formulating a digital transformation strategy", MIS Quarterly Executive, Vol. 15 No. 2, pp. 123-139.

Huizingh, E.K. (2011), “Open innovation: State of the art and future perspectives”, Technovation, Vol. 31 No. 1, pp. 2-9.

Hussinki, H., Ritala, P., Vanhala, M. and Kianto, A. (2017), "Intellectual capital, knowledge management practices and firm performance", Journal of Intellectual Capital, Vol. 18 No. 4, pp. 904-922.

Imai, K., Nonaka, I. and Takeuchi, H. (1985), "Managing the new product development process: how Japanese companies learn and unlearn", in Hayes, R.H., Clark, K. and Lorenz, C. (Eds), The Uneasy Alliance: Managing the Productivity-Technology Dilemma, Harvard Business School Press, Boston, MA, pp. 337-375.

Italian Ministry of Economic Development, Directorate-General for Industrial Policy, Competitiveness, and SMEs (2019), "Italy's legislative framework to support innovative SMEs Executive
Italian small innovative enterprises 
summary", pp. 1-19, available at: https:/www.mise.gov.it/index.php/it/impresa/piccole-e-medieimprese/pmi-innovative.

Jahanmir, S.F. and Lages, L.F. (2016), "The late-adopter scale: a measure of late adopters of technological innovations", Journal of Business Research, Vol. 69 No. 5, pp. 1701-1706.

Kaplan, R.S. and Norton, D. (1992), "The balanced scorecard: measures that drive performance", Harvard Business Review, Vol. 70 No. 1, pp. 71-79.

Katz, B., Turgut, E., Holzmann, T. and Sailer, K. (2013), "Innovation intermediaries: a process view on open innovation coordination", Technology Analysis and Strategic Management, Vol. 25 No. 3, pp. 295-309.

Kearney, G. and Mchattie, L.S. (2014), "Supporting the open innovation process in small and medium enterprises", International Journal of Entrepreneurship and Small Business, Vol. 23 No. 4, pp. 552-567.

Kianto, A. (2008), “Assessing organizational renewal capability”, International Journal of Innovation and Regional Development, Vol. 1 No. 2, p. 115-29.

Kijek, T. (2012), "Innovation capital and its measurement", Journal of Entrepreneurship, Management and Innovation, Vol. 8 No. 4, pp. 52-68.

Kim, N. and Shim, C. (2018), "Social capital, knowledge sharing and innovation of small-and mediumsized enterprises in a tourism cluster", International Journal of Contemporary Hospitality Management, Vol. 30 No. 6, pp. 2417-2437.

Klerkx, L. and Aarts, N. (2013), "The interaction of multiple champions in orchestrating innovation networks: conflicts and complementarities", Technovation, Vol. 33 Nos 6-7, pp. 193-210.

Ko, W.W.J., Chen, C.H.S., Liu, G., Nguyen, B. and Takeda, S. (2020), "IT-based product innovation strategies for small firm”, Information Technology and People, Vol. 33 No. 6, pp. 1489-1514, doi: 10.1108/ITP-07-2018-0343.

Landry, R., Amara, N. and Lamari, M. (2002), "Does social capital determine innovation? To what extent?", Technological Forecasting and Social Change, Vol. 69 No. 7, pp. 681-701.

Lavie, D. (2006), "The competitive advantage of interconnected firms: an extension of the resourcebased view", Academy of Management Review, Vol. 31 No. 3, pp. 638-658.

Li, J., Li, Y., Yu, Y. and Yuan, L. (2019), "Search broadly or search narrowly? Role of knowledge search strategy in innovation performance", Journal of Knowledge Management, Vol. 23 No. 5, pp. 809-835, doi: 10.1108/JKM-06-2018-0386.

Liu, D., Chen, S. and Chou, T. (2011), "Resource fit in digital transformation: lessons learned from the CBC Bank global e-banking project”, Management Decision, Vol. 49 No. 10, pp. 1728-1742.

Malhotra, A. and Majchrzak, A. (2019), "Greater associative knowledge variety in crowdsourcing platforms leads to generation of novel solutions by crowds", Journal of Knowledge Management, Vol. 23 No. 8, pp. 1628-1651.

Marimuthu, M., Arokiasamy, L. and Ismail, M. (2009), "Human capital development and its impact on firm performance: evidence from developmental economics", The Journal of International Social Research, Vol. 2 No. 8, pp. 265-272.

Mariz-Pérez, R.M., Teijeiro-Álvarez, M.M. and García-Álvarez, M.T. (2012), "The relevance of human capital as a driver for innovation”, Cuadernos de economía, Vol. 35 No. 98, pp. 68-76.

Mayer, R.C., Davis, J.H. and Schoorman, F.D. (1995), “An integrative model of organizational trust”, Academy of Management Review, Vol. 20 No. 3, pp. 709-734.

Mazzucchelli, A., Chierici, R., Tortora, D. and Fontana, S. (2019), "Innovation capability in geographically dispersed R\&D teams: the role of social capital and IT support", Journal of Business Research, in press, doi: 10.1016/j.jbusres.2019.05.034.

McDowell, W.C., Peake, W.O., Coder, L. and Harris, M.L. (2018), "Building small firm performance through intellectual capital development: exploring innovation as the «black box»", Journal of Business Research, Vol. 88, pp. 321-327. 
McElroy, M.W. (2002), "Social innovation capital”, Journal of Intellectual Capital, Vol. 3 No. 1, pp. 30-39.

McElroy, M.W., Jorna, R.J. and Engelen, J.V. (2006), "Rethinking social capital theory: a knowledge management perspective", Journal of Knowledge Management, Vol. 10 No. 5, pp. 124-136.

Miles, S.J. and Van Clieaf, M. (2017), "Strategic fit: key to growing enterprise value through organizational capital", Business Horizons, Vol. 60 No. 1, pp. 55-65.

Muninger, M.I., Hammedi, W. and Mahr, D. (2019), "The value of social media for innovation: a capability perspective”, Journal of Business Research, Vol. 95, pp. 116-127.

Nahapiet, J. and Ghoshal, S. (1998), "Social capital, intellectual capital, and the organizational advantage", Academy of Management Review, Vol. 23 No. 2, pp. 242-266.

Nambisan, S., Siegel, D. and Kenney, M. (2018), "On open innovation, platforms, and entrepreneurship”, Strategic Entrepreneurship Journal, Vol. 12 No. 3, pp. 354-368.

Nambisan, S., Wright, M. and Feldman, M. (2019), "The digital transformation of innovation and entrepreneurship: progress, challenges and key themes”, Research Policy, Vol. 48 No. 8, pp. 1-9, 103773.

Nunnally, J.C. and Bernstein, I. (1994), Psychometric Theory, Vol. 3, McGraw-Hill, New York, NY.

Papa, A., Santoro, G., Tirabeni, L. and Monge, F. (2018), "Social media as tool for facilitating knowledge creation and innovation in small and medium enterprises", Baltic Journal of Management, Vol. 13 No. 3, pp. 329-344.

Parida, V., Westerberg, M. and Frishammar, J. (2012), "Inbound open innovation activities in high-tech SMEs: the impact on innovation performance", Journal of Small Business Management, Vol. 50 No. 2, pp. 283-309.

Petrou, A. and Daskalopoulou, I. (2013), "Social capital and innovation in the services sector", European Journal of Innovation Management, Vol. 16 No. 1, pp. 50-69.

Petty, R. and Guthrie, J. (2000), "Intellectual capital literature review", Journal of Intellectual Capital, Vol. 1 No. 2, pp. 155-176.

Prusak, L. and Cohen, D. (2001), "How to invest in social capital", Harvard Business Review, Vol. 79 No. 6, pp. 86-97.

Richey, R.G. and Autry, C.W. (2009), "Assessing interfirm collaboration/technology investment tradeoffs", The International Journal of Logistics Management, Vol. 20 No. 1, pp. 30-56.

Rohrbeck, R., Konnertz, L. and Knab, S. (2013), "Collaborative business modelling for systemic and sustainability innovations", International Journal of Technology Management, Vol. 63 Nos 1-2, pp. 4-23.

Rothwell, R. (1992), "Successful industrial innovation: critical factors for the 1990s", R\&D Management, Vol. 22 No. 3, pp. 221-239.

Rothwell, R. (1994), "Towards the fifth-generation innovation process", International Marketing Review, Vol. 11 No. 1, pp. 7-31.

Rothwell, R. and Zegveld, W. (1985), Reindustrialization and Technology, Longman, London.

Rubera, G., Chandrasekaran, D. and Ordanini, A. (2015), "Open innovation, product portfolio innovativeness and firm performance: the dual role of new product development capabilities", Journal of the Academy of Marketing Science, Vol. 44 No. 2, pp. 1-19.

Salter, A., Criscuolo, P. and Ter Wal, A.L.J. (2014), "Coping with Open Innovation: responding to the challenges of external engagement in R\&D”, California Management Review, Vol. 56 No. 2, pp. 77-94.

Santoro, G., Mazzoleni, A., Quaglia, R. and Solima, L. (2019), "Does age matter? The impact of SMEs age on the relationship between knowledge sourcing strategy and internationalization", Journal of Business Research, in press, doi: 10.1016/j.jbusres.2019.05.021.

Sardo, F. and Serrasqueiro, Z. (2017), "Intellectual capital and firms' financial performance: a European empirical study", Business and Economic Research, Vol. 7 No. 2, pp. 1-18. 
JIC 22,3

\section{0}

Scuotto, V., Del Giudice, M., Bresciani, S. and Meissner, D. (2017a), "Knowledge-driven preferences in informal inbound open innovation modes. An explorative view on small to medium enterprises", Journal of Knowledge Management, Vol. 21 No. 3, pp. 640-655.

Scuotto, V., Santoro, G., Bresciani, S. and Del Giudice, M. (2017b), "Shifting intra- and interorganizational innovation processes towards digital business: an empirical analysis of SMEs", Creativity and Innovation Management, Vol. 26, pp. 247-255.

Shubert, P. (2019), "Joint work and information sharing in the modern digital workplace: how the introduction of 'social' features. Shaped enterprise collaboration systems", in Riemer, R., Schellhammer, S. and Meinert, M. (Eds), Collaboration in the Digital Age. How Technology Enables Individuals, Teams and Businesses, Springer, Switzerland.

Sisodiya, S.R., Johnson, J.L. and Gregoire, Y. (2013), "Inbound open innovation for enhanced performance: enablers and opportunities”, Industrial Marketing Management, Vol. 42 No. 5, pp. 836-849.

Soto-Acosta, P., Perez-Gonzalez, D. and Popa, S. (2014a), "Determinants of web 2.0 technologies for knowledge sharing in SMEs", Service Business, Vol. 8 No. 3, pp. 425-438.

Soto-Acosta, P., Colomo-Palacios, R. and Popa, S. (2014b), "Web knowledge sharing and its effect on innovation: an empirical investigation in SMEs", Knowledge Management Research and Practice, Vol. 12 No. 1, pp. 103-113.

Soto-Acosta, P., Popa, S. and Palacios-Marqués, D. (2017), "Social web knowledge sharing and innovation performance in knowledge-intensive manufacturing SMEs", The Journal of Technology Transfer, Vol. 42 No. 2, pp. 425-440.

Stewart, T. (1997), Intellectual Capital: The New Wealth of Organizations, Doubleday, New York, NY.

Subramaniam, M. and Youndt, M.A. (2005), "The influence of intellectual capital on the types of innovative capabilities", Academy of Management Journal, Vol. 48 No. 3, pp. 450-463.

Sullivan, P. (1998), Profiting from Intellectual Capital: Extracting Value from Innovation, Wiley, New York, NY.

Sveiby, K.E. (1997), "The intangible assets monitor", Journal of Human Resource Costing and Accounting, Vol. 2 No. 1, pp. 73-97.

Thompson, M. (2018), "Social capital, innovation and economic growth", Journal of Behavioral and Experimental Economics, Vol. 73, pp. 46-52.

Trainor, K.J., Andzulis, J.M., Rapp, A. and Agnihotri, R. (2014), "Social media technology usage and customer relationship performance: a capabilities-based examination of social CRM", Journal of Business Research, Vol. 67 No. 6, pp. 1201-1208.

Ulum, I., Ghozali, I. and Purwanto, A. (2014), "Intellectual capital performance of Indonesian banking sector: a modified VAIC (M-VAIC) perspective", Asian Journal of Finance and Accounting, Vol. 6 No. 2, pp. 103-123.

van Wijk, J., Zietsma, C., Dorado, S., de Bakker, F.G.A. and Martí, I. (2019), "Social innovation: integrating micro, meso, and macro level insights from institutional theory", Business and Society, Vol. 58 No. 5, pp. 887-918.

Vishnu, S. and Gupta, V.K. (2014), "Intellectual capital and performance of pharmaceutical firms in India”, Journal of Intellectual Capital, Vol. 15 No. 1, pp. 83-99.

Vrontis, D., Thrassou, A., Santoro, G. and Papa, A. (2017), "Ambidexterity, external knowledge and performance in knowledge-intensive firms", The Journal of Technology Transfer, Vol. 42 No. 2, pp. 374-388.

Wang, Z., Wang, N. and Liang, H. (2014), "Knowledge sharing, intellectual capital and firm performance", Management Decision, Vol. 52 No. 2, pp. 230-258.

Wang, C., Chin, T. and Lin, J.-H. (2020), "Openness and firm innovation performance: the moderating effect of ambidextrous knowledge search strategy", Journal of Knowledge Management, Vol. 24 No. 2, pp. 301-323, doi: 10.1108/JKM-04-2019-0198. 
Warner, K.S.R. and Wäger, M. (2019), "Building dynamic capabilities for digital transformation: an ongoing process of strategic renewal", Long Range Planning, Vol. 52, pp. 326-349.

Wenger, E. (1998), "Communities of practice: learning as a social system”, Systems Thinker, Vol. 9 No. 5 , pp. 2-3.

Wenger, E.C. and Snyder, W.M. (2000), "Communities of practice: the organizational Frontier", Harvard Business Review, Vol. 78 No. 1, pp. 139-146.

Williamson, O.E. (1989), “Transaction cost economics”, Handbook of Industrial Organization, Vol. 1, pp. 135-182.

$\mathrm{Xu}$, J. and Li, J. (2019), “The impact of intellectual capital on SMEs' performance in China. Empirical evidence from non-high-tech vs. high-tech SMEs", Journal of Intellectual Capital, Vol. 20 No. 4, pp. 488-509.

Young, J. (2012), Personal Knowledge Capital: The Inner and Outer Path of Knowledge Creation in a Web World, Elsevier.

\section{About the authors}

Roberto Chierici is Assistant Professor of Marketing at the Department of Business and Law of the University of Milan-Bicocca, Italy. He obtained his $\mathrm{PhD}$ in Business Administration, Management and Territorial Economics from the University of Milan-Bicocca in 2016. His research interests lie in the area of management studies, with a focus on social media and customer relationship management, social commerce, multichannel customer management, social media, innovation and knowledge management, and new forms of entrepreneurship. He is author of numerous international articles and he is engaged in various peer-review processes for several ranked international journals on management. Roberto Chierici is a corresponding author and can be contacted at: roberto.chierici@unimib.it

Debora Tortora, $\mathrm{PhD}$, is currently Assistant Professor of Management at the University of MilanBicocca, Italy. Her main subjects of interest concern smart and sustainable tourism, big social data, augmented reality, experience marketing, new forms of entrepreneurship. She published in several outstanding Journals and carried out consultancy activities related to strategy, marketing and communication. According to Italian ASN (National Scientific Habilitation), she received the habilitation for the Associate Professorship

Manlio Del Giudice is Full Professor of Management at the University of Rome "Link Campus". He holds a PhD in Marketing and Management at the University of Milano-Bicocca and he is affiliated as Professor of Management and Entrepreneurship at the Paris School of Business, in Paris (France), and as a Principal Investigador, at the University of Murcia, in Murcia (Spain). He serves as Director for Research and Scholarly Relations within the Euromed Business Research Institute, where he is Senior Fellow as well. He is the author of about 100 international scientific publications (including 12 monographs). He holds key positions (Editor, Senior Associate Editor, Associate Editor) in several international scientific journals on management. He has active collaborations with over 60 universities around the world (including George Washington University, Stanford University, Harvard Business School, University of Cambridge, and among others). He serves as Associate Editor for global relevant publishers such as Nature Publishing Group, Springer, Palgrave MacMillan. He has developed over the years active collaboration on marketing, technology transfer and innovation with a number of institutions (Prime Minister's Office, Department of Youth, National Research Council, US Consulate General, and Science and Technology Park of Sicily). He has held key roles on the boards of public and private consortiums and companies within the fields of avionics, advanced biotechnologies, nutraceuticals, bio-composting technologies, ICT, publishing. He has been a mentor of more than 30 spin offs in the fields of biotech, renewable energy and agribusiness. He is currently serving as Expert Evaluator for the Campania Region, for the National Research Council of Norway and for the European Commission in the areas of marketing, technological innovation and internationalisation.

Barbara Quacquarelli is Associate Professor of Organisation Studies at University of Milano Bicocca, where she teaches international business and cross cultural management. She is also Professor of Management at Italian National School of Public Administration, where she designs and delivers executive training for public managers. She is a member of the faculty of MIP, business school of Polytechnic of Milan, where she teaches Talent Acquisition and Employer Branding. She researches in diversity management, with a major focus on gender and cultures and organisational integration post
Italian small innovative enterprises 
mergers and acquisitions. She is author of numerous international books and articles, including "International Human Resources" with F. Prandstraller, "Integration of Mergers and Acquisitions in Fashion and Luxury Industry" in New Luxury Management (Palgrave), edited by F. Pini and E. Raiguad-Lacress, as well as editor, with M.C. Bombelli, of the Italian edition of "Organizational behavior" by R. Kreitner, A. Kinicki 